\title{
Flexural Performance Study of Glass Fiber Reinforced Foam Concrete with Hydrogen Peroxide
}

\author{
Jun Liu \\ Shenyang Ligong University \\ Shenyang, China
}

\begin{abstract}
In this paper, using hydrogen peroxide solution foaming method, replace part of cement with fly ash foamed concrete and glass fiber preparation, and using the SEM characterization of the glass fiber to foam concrete internal structure, the influence of glass fiber and hydrogen peroxide is discussed on the properties of foam concrete Flexural performance.Results show that the glass fiber can significantly increase the flexural strength of foam concrete, when hydrogen peroxide dosage was $6 \%, 7 \%, 8 \%$, glass fiber mixing rate was $0.15 \%, 0.10 \%, 0.05 \%$, the flexural strength of foam concrete maximum respectively, can be increased by $26.7 \%, 17.2 \%$ and $17.2 \%$;And under the same hydrogen peroxide dosage, with the increase of glass fiber volume fraction, foam concrete flexural strength presents a trend after rising first down, and the influence degree of glass fiber on the properties of foam concrete flexural impact decreases with the increase of foam concrete foaming degree.
\end{abstract}

Keywords-glass fiber; foam concrete; hydrogen peroxide; flexural performance

\section{INTRODUCTION}

Foam concrete,because of its good thermal insulation performance, is widely applied in the areas of construction projects, such as roof insulation, wall insulation, such as tunnel engineering [2], the preparation of foam concrete are toward diversified development, hydrogen peroxide solution foaming system applied in the field of foam concrete simplifies the production technology of foam concrete, reduces the cost, but also improve the quality of the foam concrete, including the size of the hydrogen peroxide content determines the size of the foam concrete foaming degree.Foam concrete still exist many defects, low flexural strength, easy cracking and other defects seriously restricted the foam concrete application in the field of roads, Bridges, etc.Fiber reinforced cement matrix composites with its good crack resistance, strengthen, toughening, fatigue resistance and other excellent properties and is widely recognized [3]. "Fiber blocking mechanism" [4], which was proposed by Romualdi, Batson and Mande, pointed out that when the crack extension to substrate interface, the fiber will produce shear stress, the constraint role of cracks in order to make cracks tend to be closed.Short glass fiber has high temperature resistance, high strength, good dispersibility, fatigue resistance performance is good wait for an advantage, has been widely used in automobile, construction, aviation

\author{
Yanlei Sun \\ Shenyang Jianzhu University \\ Shenyang, China \\ e-mail:714427477@qq.com
}

supplies, etc. [5] This article using short glass fiber mixed with hydrogen peroxide solution foaming in the foam concrete, changing the content of short glass fiber and the dosage of hydrogen peroxide,studies the influence rule of foam concrete flexural performance by short glass fiber under the different levels of foam concrete foaming degree.

\section{EXPERIMENTS}

\section{A. Raw Material}

The performance parameters of 42.5R Portland cement which is producted by Dalian onoda Co., Ltd are shown in Table I. The performance parameters of the secondary fly ash are shown in Table II [1]. The performance parameters of short glass fiber which is producted by Hangzhou hightech composite materials Co., Ltd shown in Table III. Using Hydrogen peroxide (The mass fraction of $30 \%$ ) which is producted by Tianjin Fuyu fine chemical co., LTD as the foaming agent;Using sodium sulfate(Chloride content is less than $0.1 \%$ ) which is producted by Tianjin Yongda Chemical reagent co., LTD as stable foam agent; Using building instant powder which is producted by Luoyang Mingyi polymer powder factory as binder.[6]

\section{B. The Preparation Process}

1) Foam concrete production:

Using magnetic stirrer (DF-101s) to dissolve the gelatine powder,and then seal let stand for $24 \mathrm{~h}$; After drying treatment, glass fiber will be mixed uniform under the effect of electrostatic fibre evenly distributed; [7]The next step, preparing $\mathrm{Na}_{2} \mathrm{SO}_{4}$ solution which is mixed evenly quickly with powder solution and $\mathrm{H}_{2} \mathrm{O}_{2}$ solution, and then pourring the mixture into the cement and fly ash in the matrix,in the end, pourring the mix blend into the mould quickly after mixing $25 \mathrm{~s}[8]$. The test using standard curing, and cut the blocks into standard test blocks after 48 hours curing.

2) Block test:

Flexural strength test:refer to the test method from the Ordinary Concrete Mechanics Performance Test Method Standard(GB/T50081-2002).Using 100mm*100mm*400mm non-standard cuboid specimen, the conversion factor is 0.85 , each group of three; and the flexural strength of the loading speed is set to $0.05 \mathrm{MPa} / \mathrm{s}$ [9].

SEM test: Select block particles(the size is less than 1 $\mathrm{cm}$ ) from the preparation of the foam concrete; and then 
having the the procession of metal spraying on the surface; having SEM test in the end.

\section{The ratio of basic}

\section{1) Determination of the glass fiber content}

According to the northwestern university professor $\mathrm{Xu}$ Jin-yu by studying fiber concrete in the compound material mechanics theory and the theory of fiber spacing, we obtain the calculation formula of critical volume ratio of the fiber as follow [10]:

$$
\rho_{f(c r i t)}=\frac{\delta_{b}}{\eta_{f}\left(\delta_{f u}-\varepsilon_{b} E_{f}\right)+\delta_{b}} \xi\left(1-\frac{\delta_{b}}{20}\right)
$$

Calculated from this formula, Glass fiber in the foam concrete commonly used broadly critical volume rate between $0.05 \%$ and $0.25 \%$, and the glass fiber can guarantee good dispersibility in the range. The glass fiber volume fraction this article takes is $0 \%, 0.05 \%, 0.10 \%, 0.15 \%$, $0.20 \%$, and $0.25 \%$.

\section{2) Reference mix ratio}

According to Table IV, the dosages of cement, fly ash, water cement ratio, sodium sulfate and powder are constent.And the dosages of hydrogen peroxide and glass fiber are variable. The test chooses three kinds of commonly used ratio of $6 \%, 7 \%, 8 \%$ hydrogen peroxide as the research object to study the effect of fiber content on the foam concrete under different foaming degree. [11]

\section{EXPERIMENTAL RESUlTS AND ANALYSIS}

\section{A. The relationship between flexural strength and glass fiber, $\mathrm{H} 2 \mathrm{O} 2$}

In this paper, according to the mechanical performance test, it summarizes the relationship between the flexural strength of foam concrete and the glass fiber content under the dosage of $6 \%, 7 \%$ and $8 \%$ cases with hydrogen peroxide, shown in Figure 1 (a), (b), (c):

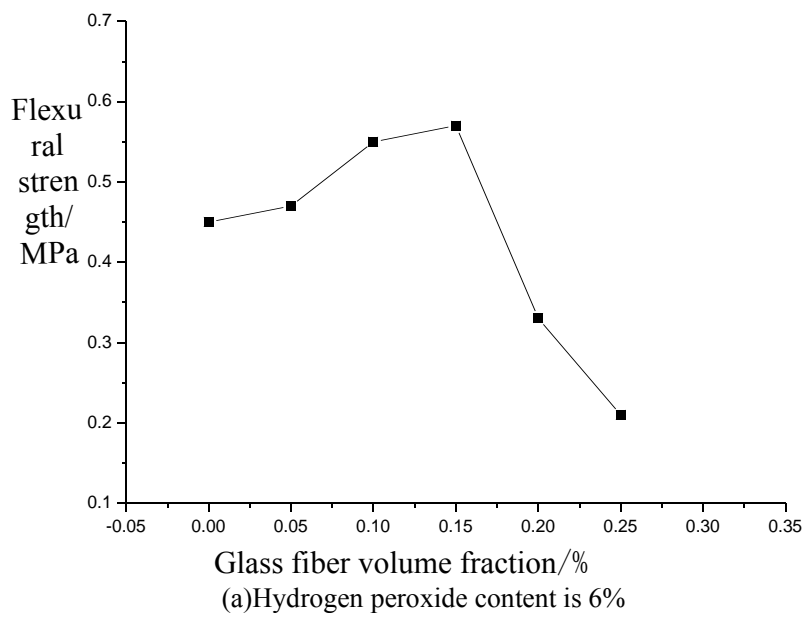

C 2015. The authors - Published by Atlantis Press 0010

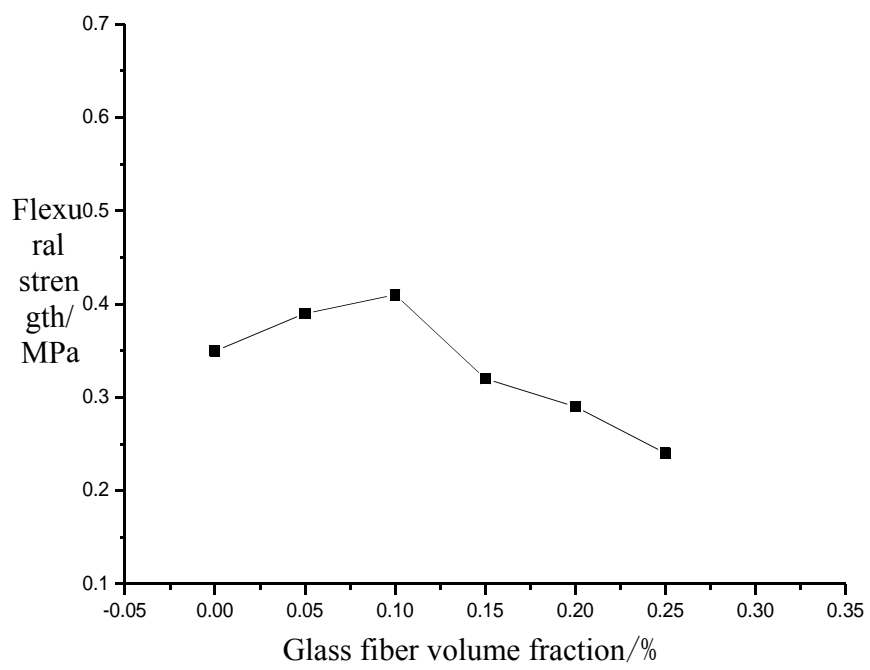

(b)Hydrogen peroxide content is $7 \%$

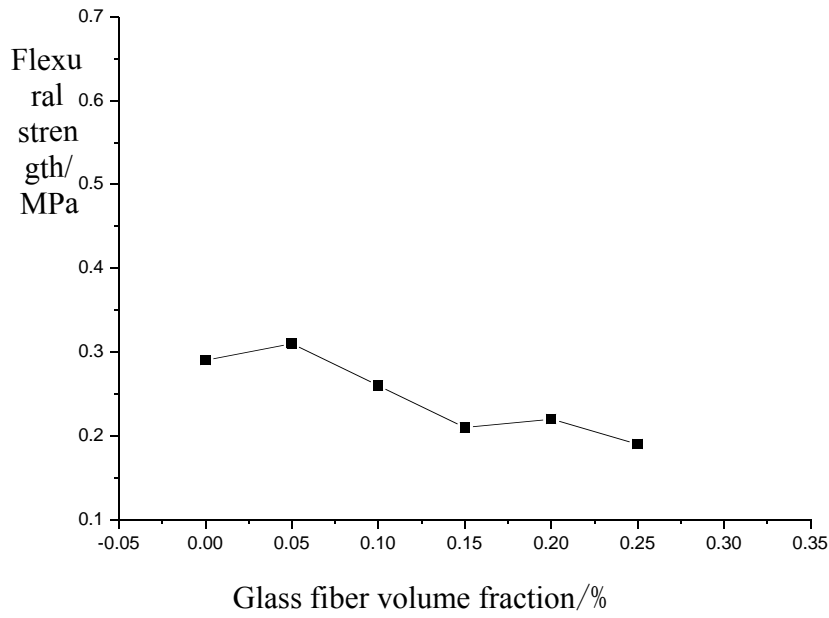

(c)Hydrogen peroxide content is $8 \%$

Figure 1. Effect of glass fiber on the flexural strength under different hydrogen peroxide

By Figure 1, the flexural strength of foamed concrete increases with the increase of the amount of glass fiber in the same amount of hydrogen peroxide. As shown in Figure 1(a), when hydrogen peroxide dosage was $6 \%$, the flexural strength of the foamed concrete increased from $0.45 \mathrm{MPa}$ to $0.57 \mathrm{Mpa}$, of which the growth rate is $26.7 \%$,under the volume fraction of glass fiber was increased from $0 \%$ to $0.15 \%$; when the volume fraction of glass fiber is more than $0.15 \%$, the flexural strength decreases rapidly.Similar to know, As shown in Figure 1(b), when hydrogen peroxide dosage was $7 \%$, The flexural strength of foamed concrete reaches the maximum $0.41 \mathrm{Mpa}$ when the volume fraction of glass fiber is $0.10 \%$,of which the growth rate of flexural strength is $17.2 \%$. In Figure 1 (c), when the hydrogen peroxide content is $8 \%$, the flexural strength of the foamed 
concrete has a small increase of $2.8 \%$ when the volume fraction of the glass fiber is $0.05 \%$, and then decreases sharply with the increase of the fiber content.

The experimental results show that the effect of glass fiber on the flexural strength of foam concrete is obvious, and the effect of glass fiber on the flexural strength of foam concrete is smaller with the increase of foaming degree. This is due to the high elastic modulus of glass fiber makes it acts as a skeleton in the foam concrete matrix, which makes the overall enhancement of the foam concrete. When the foaming degree of foamed concrete increases, the skeleton of the glass fiber is weakened, and the fiber is more easy to produce a small crack, which makes the flexural strength decrease.

\section{B. SEM scanning electron microscope analysis}

In this paper, the SEM scanning electron microscope images of partially foam concrete in the process of testing were selected, and the relationship between the flexural strength of foamed concrete and the content of glass fiber and the amount of hydrogen peroxide was described in this paper.

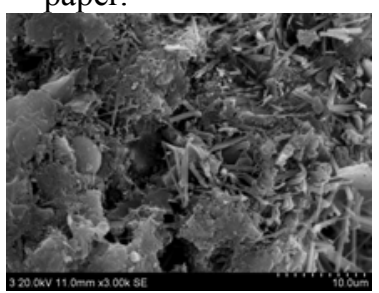

(a)SEM scan of the A2

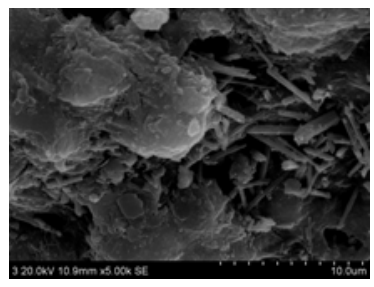

(c)SEM scan of the $\mathrm{C} 1$

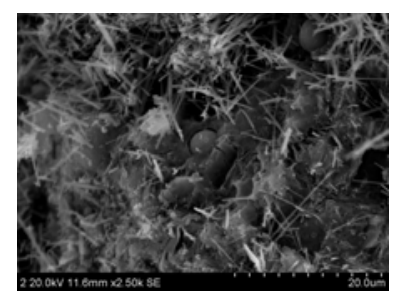

(b)SEM scan of the A5

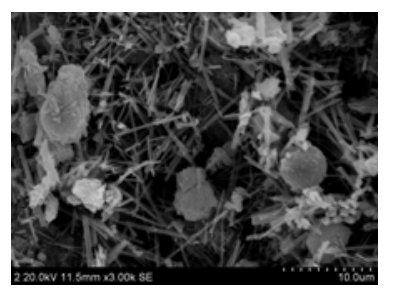

(d)SEM scan of the C5
Figure 2. Glass fiber reinforced foamed concrete under SEM scanning electron microscope

When the foam concrete foaming degree and glass fiber content are relatively small, as shown in Figure 2 (A2) SEM foam concrete particles, the picture shows that glass fiber is uniformly distributed in the foam concrete matrix, fiber and matrix are closely bonded, forming a continuous, dense fiber reinforced structure, and the fiber content is high, such as Figure 2 (b) shows that a large number of glass fiber blocking the matrix, and the fiber and matrix between the SEM, In Figure 2 (c), the SEM images show that the bonding properties of glass fiber and matrix are not obvious, and the fiber content is high, and the content of SEM is high, and the high content of glass fiber is $\mathrm{C} 5$, which shows that there is a lot of micro cracks.

Through the mechanism of fiber reinforcement, [4] can be known, when the foam concrete foaming degree is low, the surface of the glass fiber and cement matrix surface has the adsorption bond strength and the teeth together, uniform distribution of glass fiber reinforced foam concrete, the overall structure and rigidity, preventing the cracks of concrete, at the same time, the addition of fiber reinforced foam concrete, micro cracks, anti-fold performance has been greatly improved. But when the fiber content is increased, the fiber has a high elastic modulus, and the glass fiber has a very high elastic modulus. In the dry shrinkage of foamed concrete, the phenomenon of "interfacial debonding" or "fiber breaking" [11], which leads to the formation of matrix micro cracks. In the case of a high degree of foaming, glass fiber is very difficult to produce a dense mesh structure. In a certain extent, the glass fiber is blocked by the contact of the foam concrete matrix.

\section{CONCLUSION}

- Under the same hydrogen peroxide content, the flexural strength of foamed concrete increases first and then decreases with the increase of the glass fiber content, and the optimum contents of glass fiber are $0.05 \%, 0.10 \%, 0.15 \%$ with the hydrogen peroxide content being $6 \%, 7 \%, 8 \%$. When the hydrogen peroxide content is $6 \%$, the volume fraction of the glass fiber is $0.15 \%$, the flexural strength of the foamed concrete is the largest, and can be improved by $26.7 \%$.

- In the case of small foaming degree, the effect of glass fiber on the flexural strength of foam concrete is obvious, and the effect of glass fiber on the flexural strength of the foamed concrete is smaller with the increase of foaming degree.

- From the microscopic level, when the amount of glass fiber is less than the optimum, the skeleton of the glass fiber is the main aspect, the flexural strength of the foamed concrete is increased; When the content of glass fiber is greater than the optimum, the high density glass fiber can block the continuity and the bond of the concrete matrix, and the concrete is more prone to produce tiny cracks in the dry shrinkage process, which leads to the reduction of the flexural strength of the foamed concrete.

\section{REFERENCE}

[1] The construction industry standard of the people's Republic of China, "266-2001. JG/T", the Ministry of housing and urban and rural construction of the people's Republic of China, 2011-10-1.

[2] W. X. Wang, "Correlation and the composition, density and strength of foam concrete," China Building Materials Science Research Institute, the green building materials National Key Laboratory, 2009-10.

[3] X. X. Chen, S. G. Zhou, and P. Xu, "Study on the effect of polymer and fiber on the crack resistance of mortar," new building materials, 2008-12, vol. 13 (4), pp. 13-16.

[4] Y. Gong, and Z. J. Xu, "Fiber reinforced concrete and fiber reinforced mortar," China Building Materials Industry Press, 2005-6.

[5] F. Y. Yang, Z. Y. Lu, S. He, and Y. H. Niu, "Study on the performance of ultra light EPS composite foam concrete," concrete and cement products, 2012-5, vol. 5, pp. 9-12. 
[6] W. Tan,T. W. Wei,M. Chen, and H. F. Liu, "Research on the construction of Shanxi," 2013-8, vol. 39/24, pp. 129-130.

[7] F.Y. Yang, "Study on the influence factors of foam concrete properties," Southwest University of Science and Technology, 2012-4.

[8] J. J. Wang, Q.S. Rao, and S.M. Jia, "Shrinkage performance test, Lanzhou Institute of technology of foam concrete," 2014-4, vol. 21 (2), pp. 31-34.
[9] Z. M. Zhou, "High strength foam concrete research," Hunan University, 2011-5.

[10] J. Y. Xu,Z. W. Li,G. X. Zhang, and M. Li, "Theoretical derivation of the critical volume fraction of fiber," concrete, 2011-10, vol. 34 (6), pp. $522-528$.

[11]X. Y. Jiang, and Y. Q. Pei, "Analysis of the interfacial mechanical properties of fiber and matrix," Southwest Jiao Tong University, 20125.

TABle I. Portland Cement Technical Indicators

\begin{tabular}{llllllll}
\hline \multirow{2}{*}{ Label } & \multirow{2}{*}{ Stability } & \multicolumn{2}{l}{ Setting time } & & \multicolumn{2}{l}{ Compressive } & \multicolumn{2}{c}{ Flexural strength (MPa) } \\
\cline { 2 - 8 } & & Initial set & Final set & $3 \mathrm{~d}$ & $28 \mathrm{~d}$ & $3 \mathrm{~d}$ & $28 \mathrm{~d}$ \\
\hline $\mathrm{P} \cdot \mathrm{O} 42.5$ & Qualified & $45 \mathrm{~min}$ & $8 \mathrm{~h} 57 \mathrm{~min}$ & 27.8 & 52.5 & 3.5 & 8.5 \\
\hline
\end{tabular}

TABLE II. Fly Ash TeChNicAl Indicators(\%)

\begin{tabular}{ccccc}
\hline Fineness $(45 \mu \mathrm{m}$ Sieve allowance $)$ & Water requirement radio & Ignition loss & $\mathrm{SO}_{3}$ & Water content \\
\hline 20 & 95 & 7.0 & 1.0 & 0.8 \\
\hline
\end{tabular}

TABLE III. Short Glass Fiber Technical Indicators

\begin{tabular}{|c|c|c|c|c|c|c|c|}
\hline $\begin{array}{l}\text { Specifications } \\
(\mathrm{mm})\end{array}$ & $\begin{array}{c}\text { Fracture } \\
\text { strength (GP } \\
\text { a) } \\
\end{array}$ & $\begin{array}{c}\text { Modulus of } \\
\text { elasticity ( } \mathrm{GPa} \\
\text { ) }\end{array}$ & $\begin{array}{l}\text { Diameter } \\
(\mu \mathrm{m})\end{array}$ & $\begin{array}{c}\text { Alkali content } \\
(\%)\end{array}$ & $\begin{array}{c}\text { Melting } \\
\text { point }\left({ }^{\circ} \mathrm{C}\right)\end{array}$ & $\begin{array}{c}\text { Density }\left(\mathrm{g} / \mathrm{cm}^{3}\right. \\
)\end{array}$ & $\begin{array}{l}\text { The mass } \\
\text { fraction of } \\
\mathrm{ZrO}_{2}(\%)\end{array}$ \\
\hline 25 & 2.8 & 86 & 13 & $\leq 7$ & 168.3 & 2.68 & 16.4 \\
\hline
\end{tabular}

table IV. Reference Mix Proportion of Fonmed Concrete

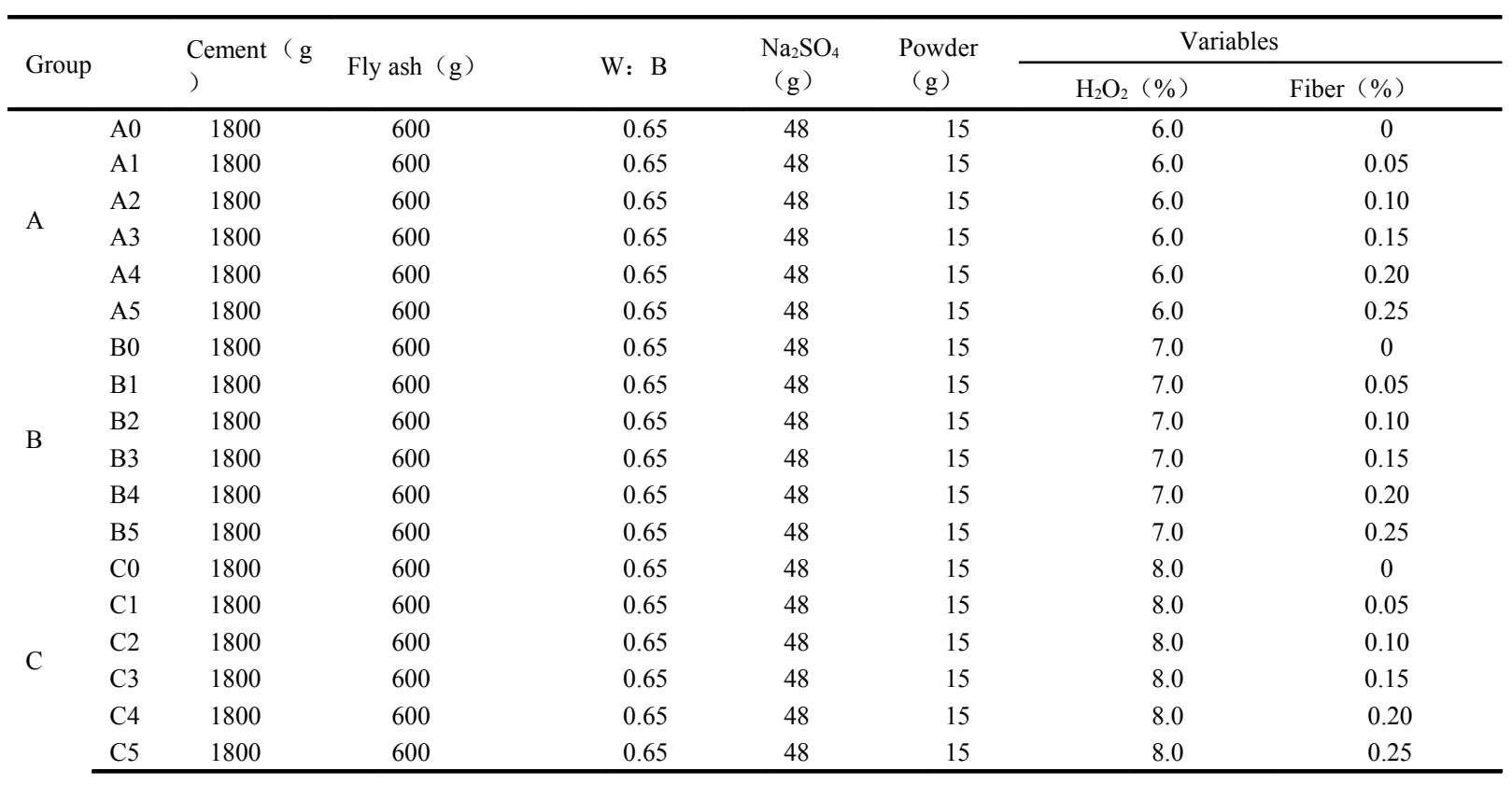

